\title{
Improving Academic Writing in Nursing Education
}

\author{
Janet Mattsson $^{1}$ \\ ${ }^{1}$ Department of Health and Technology Development, Sweden \\ Correspondence: Janet Mattsson, Department of Health and Technology Development, Sweden
}

Received: September 2, 2016

Accepted: September 30, 2016

Online Published: October 7, 2016

doi:10.5430/ijhe.v5n4p96

URL: http://dx.doi.org/10.5430/ijhe.v5n4p96

\begin{abstract}
Background: At a specialist nursing education in intensive care, located at a University college in Sweden, there was a desire among the faculty to develop their ability to support specialist nursing students in their academic development, as well as in their academic writing, to improve the overall quality of the master theses. A quality improvement design, the Plan, DO, Study, Act (PDSA) cycle was applied. Two graduating classes of specialist nursing students and two faculty members were involved in the quality improvement of academic writing. The result of the study showed improved academic writing and improved student satisfaction in the master thesis writing process.
\end{abstract}

Keywords: Quality improvement, Intervention, Self- directed learning, Evidence based education, Thesis writing

\section{Introduction}

The present paper focuses on a change within the faculty on how to tutor the nursing students to become more self-directed and satisfied in their master thesis process. Research (Borglin \& Fagerstrom, 2012) highlights that nursing students report that writing their master thesis is one of the most difficult moments in their education. What is more, nursing students also lack preparedness to write a thesis (Friberg \& Dahlborg, 2013; Kapborg \& Berterö; 2002 Borglin \& Fagerstrom, 2012). Kapborg and Berterö (2002) also raise awareness of general problems such as poor spelling and grammar, as well as inadequate structure. On the tutors' behalf there is a lack of knowledge of how to raise students' awareness and deepen their understanding of the outcome and meaning of the different scientific approaches (Borglin \& Fagerstrom, 2012). On the other hand, a prerequisite for student satisfaction and good progression in the students' thesis writing is an adequate matching of the student's research question and the tutor's expertise in this area, accompanied with good tutoring skills, good interpersonal relationships between student and tutors (Ives \& Rowley, 2005). This highlights the importance of tutors comprising both a sound and deepened knowledge in nursing science as well as in pedagogy. In addition, an organizational coherent framework in tutoring, assessment and grading of the thesis writing process needs to be negotiated and agreed upon in the community of practice. At a specialist nursing education in intensive care located at a University college in Sweden, there was a strong desire among the faculty members to implement a self-directed, scientific approach towards the process of writing a master thesis, and developing the teachers' tutoring ability in order to support specialist nursing student's in their academic development, as well as in their academic writing. It was important that the process of influencing teachers' thinking should be included in the communities within which they practice their everyday work as tutors. The overall objective was to improve the overall quality of the master thesis process as well as the written theses at the University College.

\section{Theoretical Framework}

Students in any context don't get into the thesis writing course empty handed. They bring with them pre-existing knowledge, skills, attitudes and mindsets. This understanding is viewed as the starting point for the student's own learning (Bransford et al., 1999) and the tutor should strive to facilitate the students to deepen and develop new knowledge as well as integrate it with their older knowledge. One could assume such an integration to be easier to facilitate if the tutors have profound understanding of the theoretical foundations underpinning the learning, as well as the phases a thesis student completes. From a constructive perspective, learning is considered to be both individual and social (Mann et al., 2011). Learning can be understood as an individual and a collective endeavor, where the individual axle of learning includes theories of cognitive psychology (Shuell, 1986; Bruning et al., 1999), surface and deep learning (Marton \& Booth, 2000), reflective learning (Brockbank \& McGill, 2007; Mezirow, 1991), self-directed learning (Garrison, 1997; Merriam, 2004) and transformational learning (Mezirow, 1991). The tutor has 
thus a key role in facilitating the students' advancing their knowledge from their point of departure until the end of their thesis. The writing process might be very different depending on the student, the tutor, the group that is tutored and working together.

\subsection{Tutorial Situations and Pedagogical Underpinnings}

Tutoring is a pedagogical meeting between the student and the tutor, a meeting that may look very different depending on the participants and the context. One of the most important responsibilities a tutor has is to design the tutorial to support and challenge the student to reach the learning outcomes, based on the pedagogical model that seems fruitful (Dysthe, 2002). The tutor is expected to, through knowledge and experience, use different pedagogical methods to help students to operationalize and transfer their theoretical knowledge into another context, writing and discussing science (Gimenez, 2011; McKeough et al., 2013). This does not occur instantaneously, it requires an active process that can be stimulated with different pedagogical approaches. For instance, Dysthe (2002) advocates a model that emphasizes the maturity and understanding through aware tutoring, which means to meet the student's learning needs and support a deepened knowledge development, to gain new knowledge as well as foster independence. Säljö (2001) emphasizes the importance of having a dialogue with the tutor and the student to bring the student from the current level, to the next level of knowledge. Despite the approach taken it is advantageous with an integrated and supportive conceptual framework and a curriculum that clearly guides the student and tutor through the thesis writing process (Hodges \& Kuper, 2012). Kapborg and Berertö (2002) suggest that well written criteria can increase the quality of the thesis writing as it provide the tutors with guiding when tutoring and assessing the thesis writing. Through the writing process the tutor also needs to be a motivator in various ways. It might consist of coaching, guiding, encouraging, challenging, critically relating to the student's work, enabling students to learn together, etc. (Gatfield., 2005; Pintrich., 2013). Access to learning resources such as libraries, databases, lectures, study guides, other experts, seminars, etc., may increase the students' ability to complete their thesis writing on a satisfactory level. Students also come from different cultures and with different needs which requires the faculty to continuously develop how learning and knowledge can be understood in different cultures and operationalized in different ways in a thesis (Caroll \& Ryan., 2007). These ambitions requires that tutors constantly seek new knowledge and understanding of what it is to tutor and how it is to be a student in the tutorial situation.

\subsection{Strengthen Academic Writing}

To improve the quality of student performance in the thesis writing, the tutors' expertise and tutoring capability requires development (Friberg and Dahlborg, 2013). If tutors become better at linking theory to the thesis writing, it can lead to a better guidance for students and increased satisfaction among teachers. To develop theoretical knowledge Gimenez (2011) suggests that the tutors should broaden their perspective and abandon the positivistic connection with the medical perspective that permeates nursing research, which focuses heavily on problem solving.

Friberg and Dahlborg (2013) argues that a prerequisite to improve academic thesis writing is that students learn how a scientific article is structured ,then it is easier for them to structure and write as such. Students can be tutored to become more self-directed in their thesis writing through other means than the ordinary student-tutor situation during thesis writing (Miedijensky \& Lichtinger, 2016). This way of arranging the pedagogical process involves changing the content and structure in the tutoring situations and for example arranging weekly or monthly seminars or workshops for the students. Students can in this way increase their awareness of theoretical perspectives, such as the difference between qualitative and quantitative design and theoretical frameworks. Through these pedagogical methods students realize that nursing research should be used to improve caring for the patient (Friberg and Dahlborg, 2013; Miedijensky \& Lichtinger, 2016). To strengthen the students in critical thinking and academic writing the tutoring and assessment throughout the education should support this learning and the tutor should adjust their own tutoring to the level they expect the thesis to reach (Kapborg and Berterö, 2002; Dysthe, 2002). Correlating students' critical thinking to clinical training and academic studies, thesis writing, debate, questioning, problem solving and small group activities can be beneficial to the development of critical thinking (Borglin \& Fagerstrom, 2012). When tutors increased their skills, such as increased ability to critique and give relevant assessment on thesis writing, satisfaction became greater. Monthly seminars to discuss challenges in the tutoring situation have been fruitful in strengthening the tutors in the tutoring role (Friberg \& Dahlborg, 2013; Miedijensky \& Lichtinger, 2016). If tutors become better at linking theory to thesis writing, it can lead to better guidance of students and increased satisfaction among teachers.

\subsection{Ethical Aspects in Tutoring}

Being a tutor includes constant ethical decisions, some captured and decided upon in the situation at hand, some more reflected. Power is a perennial perspective. Being in a tutoring position means being in a power position, as 
tutors are expected to be professional and knowledgeable in the field. Tutors have the power to support or hinder the student through the comments given about the student's work. How these views are expressed and clarified are of importance. Students have the power to decide for themselves what and how much of the proposed comments that they will allow to influence their continued thesis writing. This can create conflicts or a well-functioning tutorial, seemingly without a ripple. Usually one might expect a certain tension to arise from time to time during tutorials until completion of the thesis writing. To avoid excessive conflicts and disappointments, it is good to discuss what is expected of the tutor and student relationship from both perspectives, and how students want their feedback to be able to draw the most benefit from it. Trying to adapt the feedback to the individual student is a good start. The tutoring role can be designed in a variety of ways with beneficial learning outcomes. Three of the basic conditions is to be flexible and knowledgeable as well as building a trusting and inclusive relationship with the student (Ives \& Rowley., 2005). From a pedagogical perspective, this does not come easy. Sometimes the tutor is expected to be so flexible and accommodating through tutoring that it will jeopardize the structure of the tutoring as it becomes fuzzy and the student will not benefit from tutoring at all. As a tutor you have the privilege to follow another person's learning. Someone who is supposed to strengthen someone else's critical thinking and academic writing. In order to achieve this common goal, active discussion and interactionnis required, openness towards the individual student as well as the student is the entire program (Kapborg \& Berterö, 2002; Dysthe, 2002). As a tutor, you should be open to the group's balance of power, dynamics and feedback to each other, how it is done and what level it reaches. Which leads to the aim of the study: to increase the specialist nursing students' scientific writing in the master thesis course.

\section{Method}

The study was carried out during two specialist nursing education programs in intensive care that followed upon each other. The Plan, DO, Study, Act (PDSA) cycle is widely used in quality improvement in healthcare and industry (Ogrinc, et al., 2012). The improvement method is often used when one wants to improve a process, in this case the time frame for the PDSA cycle ranged between January 2014 and June 2016. Students in the first specialist nursing education in intensive care comprised 20 students, 17 women and three men. The second specialist nursing education in intensive care comprised 18 students, 14 women and four men. Since this is a quality improvement process, no ethical permit is required in accordance with Swedish law and the Act on Ethical Review of Research Involving Humans (SFS 2003: 460) and the Personal Data Act (SFS 1998: 204). However all participants were asked for informed consent.

\subsection{Data Collection}

The PDSA cycle where followed according to the suggestions made in Ogrinc, et al., (2012). The cycle begins with the Plan step. This involves identifying a goal or purpose, formulating a theory, defining success metrics and putting a plan into action. The first step was to evaluate the master thesis writing course in a post graduate specialist nursing program at a University College, from the students' perspective. Previous students $(\mathrm{N}=20)$ in the master thesis writing course had been asked three questions upon completion of the course. They were asked:

1. What have you learnt during the training that you think is most meaningful to you?

2. What in the program has supported you in your learning the best?

3. What changes in the program would have improved your ability to learn?

Student responses were analyzed thematically as suggested by Brown and Clark (2006). The written responses were coded and grouped into themes. The codes were classified into three major themes (1) factors that yielded learning during the thesis writing course, (2) factors that yielded structure for learning and (3) factors that yielded change for learning. Each of the themes conveyed specific content.

Factors that yielded learning during the thesis-writing course highlights that students thought they learnt the most from collaboration with each other outside tutoring situations. Factors that yielded structure for learning highlighted the inconsistence in the pedagogical process, unclear tutoring and too broad advices in methodology approaches. Factors that yielded change for learning highlighted the importance of workshops that allowed the students to try different scientific approaches. Also the pedagogical ability of the tutor was highlighted as an important factor change for learning.

Next the grading from the previous master thesis course was evaluated, all had been graded a pass in a three graded scale (failed, pass, pass with distinction) upon completion. Also the assessment template was read with one question in mind: is it easy to understand and follow? We also evaluated the specialist nursing program as a whole regarding academic writing, scientific discussions and literacy. Next it became important to clarify what changes needed to be made and what measures that would be used to measure improvements in the students' thesis writing abilities. In 
accordance with the literature, we decided to start the students' academic writing and scientific discussions right at the start in the following intensive care program. We also decided to ask the same three questions as a student satisfactory follow-up with the thesis writing and their learning throughout the course. We also decided that the grading of the theses would yield as a quality mark of the scientific education provided, since the same individual examiners assess all master theses.

These activities were followed by the DO step, in which the components of the plan were implemented. In this study we acted on the findings from the first step (N 20) and started with academic writing and article reading as well as scientific discussions in the first course of the next intensive care course in accordance with suggestions made by (Friberg and Dahlborg, 2013; Miedijensky \& Lichtinger, 2016). We clarified the principles for theses writing and assessment, to clarify the knowledge students are expected to acquire through science courses and thesis writing in the specialist nursing program, as suggested by Kapborg and Berertö (2002) and Hodges and Kuper (2012).

It also required an active process of discussing in the faculty, motivating, in-depth understanding of the meaningful writing students do in their theses, etc. Which lead us to reorganizing the tutoring situations, beginning with a discussion as suggested by Ives and Rowley, (2005) concerning the different phases of tutoring and thesis writing with the student, to clarify what most students undergo in frustration and learning on their way from start to complete thesis. Being aware of the student perspective, how it is to feel that you are losing grip on something unintelligible and the need to reach an understanding to continue to write your thesis might be a good starting point for a pedagogical meeting with the student. We also changed the way of tutoring from a more conventional way where tutor and students meet and discuss the student's writing and corrections are suggested, to a more participatory and self-directed method. We planned for all students to work in a structured group with a thematically directed peer learning in the morning connected with a tutorial seminar held by two tutors together, with different expertise in scientific methods, in the afternoon. Each tutor was matched with a student according to what subject or area the student wanted to write about and what scientific approaches they were going to use. If the tutor were an active researcher in the scientific approach chosen by the student, tutor and student were matched. The aim of the tutorial seminar was to follow up and deepen the scientific discussion students began in their morning session, bringing up issues discussing and problematizing them from different scientific approaches. This pedagogical model allows the student to learn and process text and content in various ways. Both the individual cognitive need for knowledge and needs of the group are exploited. Through this kind of tutorial, we used what Mann et al., (2011) describe as the cognitive knowledge axel and the social knowledge axel. There is also time for reflection, which is very important in the continuing thesis writing.

Next comes the Study step, where outcomes were monitored to test the validity of the plan for signs of progress and success, or to handle problems and areas of improvement. During seminars students and tutors discussed thesis writing, gave feedback and followed up on previous feedback, according to the plan discussed in the previous step. All students gave written peer feedback to each other in relation to the assessment template and according to what was agreed upon during the seminars. All students also had their own tutor to turn to for further discussions if needed. During seminars tutors evaluated the progress of the student's thesis writing in accordance with the assessment template.

The final Act step closes the cycle and can also be viewed as a result of the process itself, integrating the learning generated by the entire process. In this study the last step contained a new evaluation of the students' satisfaction with thesis writing. The tree questions asked upon completion of the latter course (N 18) were again:

1. What have you learnt during the training that you think is most meaningful to you?

2. What in the program has supported you in your learning the best?

3. What changes in the program would have improved your ability to learn?

In this last step grading of theses was viewed as a result as we earlier in the process decided the grading's to be a quality mark of the scientific education provided, as the same individual examiners assess all master theses.

Student responses in the second evaluation were classified into three major themes. The first theme (1) factors of understanding, showed that students felt that the most meaningful learning was to understand and evaluate scientific papers. The second theme (2) factors of evidence, resulted in students saying the importance of being evidence based in the coming profession as specialist intensive care nurses supported them the most. Students highlighted the student seminars as the most fruitful learning activities to understand and implement their new scientific knowledge in relation to their new profession. An important factor in this theme was the feeling that they could ask their peers questions they thought the tutor would find odd. They also liked the tutor seminars as they clarified and deepened their understanding about different scientific interpretations. The last theme, (3) improvement, highlighted students' understanding of 
knowing their weaknesses. The students embraced their shortcomings and asked actively for clarifications, more workshops on data analysis and ontology as well as hands on tutoring to learn more regarding their weaknesses. A review of the grading of the master thesis revealed that 13 students were graded pass, and five students were graded pass with distinction.

\section{Discussion}

In this research based quality improvement work the improvement team has taken the pedagogical methods suggested in the literature and implemented them in a real-world learning environment. Tutors and examiners involved in the quality improvement project, were the same persons that were involved in the former master thesis writing course. This was a deliberate action to change as few conditions as possible and with the allocated recourses through pedagogical changes, reach a higher quality in completed master theses as well as higher student satisfaction. One can argue that starting a quality project raises the awareness of quality and tutoring, which affects the outcome positively. It might be so, on the other hand it is a continuing and ongoing discussion in an academic faculty how one can improve courses, oneself or other things that might increase the quality of the education as such.

The results in this study suggests that there has been a quality improvement in the thesis writing course and that students feel more satisfied and also feel they have learnt more in comparison to the former students. What's more is the change in the students' answers about their own strengths and weaknesses as well as learning needs from the first specialist nursing education to the second nursing education. This shows an academic maturing and deeper insight in the needs of their new professional role and what knowledge is needed to become a specialist intensive care nurse, taking care of patients with critical conditions. Also the gradings show that the latter students were graded higher by the same examiners that graded previous courses. What also came out from the study is that our University College now has instructions to support tutors and students in this process, frames that proved beneficial for learning in accordance with Hodges' and Kupers', (2002) conclusions. What is next, these four steps will be repeated over and over again as part of a never-ending cycle of continuous improvement. Tutors will be used to adjusting goals, changing methods or even reformulating a theory of learning in the thesis writing course.

Commuting between general and specific problem areas in the main area in relation to the intensive care context is a recurring theme in specialist education. It is not only associated with the degree course, even though it may become more evident in that course. As Dysthe (2002) pointed out it is about the alignment and maturing of scientific understanding during an education that makes the difference. In the latter specialist nursing education we started already in the first course to integrate a scientific approach as a thread through the education based on the students' own activity in regard to intensive care. The relationship with the scientific approach, the ethical approach and the social perspective are emphasized and different scientific methods are being studied and practiced through various workshops throughout the program. All learning activities are now based on the student's own need of what to learn (Bransford et al., 1999) and problematized in relation to the student's learning needs. We also added the possibility for the students in the thesis writing course to meet and scientifically discuss their own thoughts about their thesis writing process with the researchers at the University College. This is highlighted as important by Ives and Rowley, (2005). It gives the student a possibility to discuss research, problems, design methods and analyzis with professional researchers and it opens up interesting discussions related to practical hands on discussions as well as discussions about scientific writing. During the master thesis course we also changed the tutoring in accordance with Friberg and Dahlberg's (2013) suggestions to facilitate the students self-directed learning. We implemented student workshops, structured in such a way that students receive an agenda referring to what part of the thesis needs to be worked through, before the tutorial. This pedagogical method is intended to support the student self-directed knowledge development during the thesis writing. It strengthens their ability for investigative approaches. A form of peer learning and learning collaboration is used, thus requiring the students to actively get involved and take responsibility for their own learning while they support their fellow students in their thesis writing. The students are in this way practicing scientific writing in order to apply and critically examine research within the intensive care field related to nursing as well as gaining an understanding of different paradigms in the field at the same time. The completed master theses show students' own knowledge and skills to develop and apply a scientific approach in relation to their own field that requires a critical approach to their own context. Something that we found had increased in the latter thesis writing course where that the grading came out higher than in the former course. We aimed for the students to develop an understanding of key issues and different perspectives that exist within the main field of nursing, throughout their entire specialist education. When students work on different concepts and issues related to nursing they are encouraged to work from and relate to their own specialist area, intensive care. This implies that they have to acquire knowledge in a more general level in the main field and then deepen their knowledge and become specific in relation to the issues studied in the specific course within the program. We also 
clarified the assessment criteria's in accordance with Kapborg and Berertö (2002) suggestions. This lead to a clearer view of what key abilities should be assessed in different ways in the thesis. Scientific, social and ethical aspects, shown through implementation, argumentation and how they are linked to the intensive care context. Demarcation of and critical approach in the thesis writing shows insight into the possibilities and limitations the chosen scientific approach provides. Insight into the role of science in society and people's responsibility for how it is used is indicated by the relevance of project selection, discussion of implementation of the results and awareness emerges of their own role as specialist nurses in intensive care.

However, there are always improvements to be made and one of the remaining key factors of continuing quality development is to have an ongoing discussion on how the faculty members can contribute to that each student reaches a good level of scientific knowledge and a critical approach towards research. How can every tutor in an academic way, and as a tutor design, help the student achieve the learning outcomes and show them that they can perform at the level required to pass the masters level?

\section{Concluding Remarks}

In this paper we have shown how an improvement strategy can be used as base for a systematic research study of teaching and learning processes, implementing and influencing teachers' thinking in education during ongoing education. And at the same time increasing the quality of the students' academic writing and scientific knowledge based on a scientific and strategic approach.

\section{References}

Benner, P., \& Wrubel, J. (1989). The Primacy of Caring: Stress and coping in health and illness. Menlo Park, Calif.: Addison-Wesley Pub. Co.;

Borglin, G., \& Fagerstrom, C. (2012). Nursing students' understanding of critical thinking and appraisal and academic writing: A descriptive, qualitative study. Nurse Education in Practice, 12, 356-360. http://dx.doi.org/10.1016/j.nepr.2012.04.009

Bransford, J.D., Brown, A. L., \& Cocking, R. R. (1999). How People Learn: Brain, Mind, Experience, and School. National Academy Press.

Brockbank, A., \& McGill, I. (2007). Facilitating reflective learning in higher education. McGraw-Hill Education (UK).

Braun, V., \& Clarke, V. (2006). Using thematic analysis in psychology. Qualitative Research in Psychology, 3, 77-101. http://dx.doi.org/10.1191/1478088706qp063oa

Bruning, R. H., Schraw, G. J., \& Ronning, R. R. (1999). Cognitive psychology and instruction. Prentice-Hall, Inc., One Lake Street, Upper Saddle River, NJ 07,458 ${ }^{\text {th }}$.

Carroll, J., \& Ryan, J. (Eds.). (2007). Teaching International Students: Improving learning for all. Routledge.

Dysthe, O. (2002). Professors as mediators of academic text Cultures: An interview study with advisors and master degree students in three disciplines in a Norwegian university. Written Communication, 19(4), 485-536. http://dx.doi.org/10.1177/074108802238010

Friberg, F., \& Dahlborg-Lyckhage, E. (2013). Changing Essay Writing in Undergraduate Nursing Education through Action Research: A Swedish example. Nursing Education Perspectives, 34; 4. http://dx.doi.org/10.5480/1536-5026-34.4.226

Garrison, D.R. (1997) Self-directed learning: Toward a Comprehensive Model, Adult Education Quarterly, 48(1) 18 -33. http://dx.doi.org/10.1177/074171369704800103

Gatfield, T. (2005). An Investigation into PhD Supervisory Management Styles: Development of a dynamic conceptual model and its managerial implications. Journal of Higher Education Policy and Management, 27(3), 311-325. http://dx.doi.org/10.1080/13600800500283585

Gimenez, J. (2012). Disciplinary epistemologies, generic attributes and undergraduate academic writing in nursing and midwifery. Higher Education, 63, 401-419. http://dx.doi.org/10.1007/s10734-011-9447-6

Hamrin, E., Kihlgren M., Rinell Hermansson, A. \& Östlinder, G. (ed.). (2014). When nursing was science: the first decades from 1970 to 2000. (1st ed.) Stockholm: Liber.

Hodges, B. D., \& Kuper, A. (2012). Theory and practice in the design and conduct of graduate medical education. Academic Medicine, 87(1), 25-33. http://dx.doi.org/10.1097/ACM.0b013e318238e069 
Ives, G., \& Rowley, G. (2005). Supervisor selection or allocation and continuity of supervision: Ph. D. students' progress and outcomes. Studies in Higher Education, 30(5), 535-555. http://dx.doi.org/10.1080/03075070500249161

Jackson, D., Darbyshire, P, Luck, L., Peter K. (2009). Intergenerational Reflections on doctoral supervision in nursing. Contemporary Nurse 32(1-2): 83-91. http://dx.doi.org/10.5172/conu.32.1-2.83

Kapborg, I., \& Berterö, C. (2002). Critiquing Bachelor Candidates' theses: Are the criteria Useful? International Nursing Review, 49, 122-128.

Kolcaba, K., \& Steiner, R. (2000). Empirical evidence for the nature of holistic comfort. Holistic Journal of Nursing, 18(1), 46-62. http://dx.doi.org/10.1177/089801010001800106

Mann, K. V., Dornan, T., \& Teunissen, P.W. (2011). Perspective of Learning 'in Dornan, T.

Mann, K. V., Scherp Bier, A. J. J. A., \& Spencer, J. (eds). Medical education: theory and practice. Elsevier.

Marton, F. Booth, S. (2000). On learning. Lund: Studentlitteratur.

McKeough, A., Lupart, J.L. \& Marini, A. (2013). Teaching for Transfer: Fostering generalization in learning. Routledge.

Merriam, S. B. (2004). The role of cognitive development in Mezirow's transformational learning theory. Adult Education Quarterly, 55(1), 60-68. http://dx.doi.org/10.1177/0741713604268891

Mezirow, J. (1991). Transformative dimensions of adult learning. Jossey-Bass, 350 Sansome Street, San Francisco, CA 94104-1310.

Miedijensky, S., \& Lichtinger, E., (2016). Seminar for master's thesis projects: promoting students's self-regulation. International Journal of Higher Education. 55(4), 13-24. http://dx.doi.org/10.5430/ijhe.v5n4p13

Murphy, K. M., \& Topel, H. R. (Eds.). (2010). Measuring the gains from Medical Research: An economic approach. University of Chicago Press.

Ogrinc GS, Headrick, LA, Moore SM, Barton AJ, Dolansky, MA, Madigosky, WS: Fundamentals of Health Care Improvement: A Guide to Improving Your Patient's Care, 2nd Ed., Oak Brook Terrace, IL: Joint Commission; Institute for Healthcare Improvement, 2012.

Phillips, E., \& Pugh, D. (2010). How to get a PhD: A handbook for students and Their Supervisors. McGraw-Hill Education (UK).

SFS 1998: 204. Personal Data Act. Stockholm: Ministry of Justice. Retrieved Januari 16 from http://www.riksdagen.se/sv/Dokument- Legislation / Laws / Svenskforfattningssamling / Personal Data Act-1998204_sfs-1998-204 /

SFS 2003: 460. Act on ethical review of research involving humans. Stockholm: Ministry of Education. Retrieved January 16 from http://www.riksdagen.se/sv/Dokument- Legislation / Laws / Svenskforfattningssamling / Law-2003460-of-etikprovning_sfs-2003-460 /

Shuell, T. J. (1986). Cognitive conceptions of learning. Review of Educational Research, 56(4), 411-436.

Säljö R. (2000). Learning in practice. A socio-cultural perspective. Stockholm.: Prism. http://dx.doi.org/10.3102/00346543056004411 